\title{
Arsenic Trioxide Regimen
}

National Cancer Institute

\section{Source}

National Cancer Institute. Arsenic Trioxide Regimen. NCI Thesaurus. Code C159991.

A chemotherapy regimen consisting of arsenic that may be used in the treatment of acute promyelocytic leukemia (APL). 